\title{
Sulphation and secretion of the predominant secretory human colonic mucin MUC2 in ulcerative colitis
}

\author{
B J-W Van Klinken, J-W G Van der Wal, A W C Einerhand, H A Büller, J Dekker
}

\begin{abstract}
Background-Decreased synthesis of the predominant secretory human colonic mucin (MUC2) occurs during active ulcerative colitis.

Aims-To study possible alterations in mucin sulphation and mucin secretion, which could be the cause of decreased mucosal protection in ulcerative colitis.

Methods-Colonic biopsy specimens from patients with active ulcerative colitis, ulcerative colitis in remission, and controls were metabolically labelled with $\left[{ }^{35} \mathrm{~S}\right]$-amino acids or $\left[{ }^{35} \mathrm{~S}\right]$-sulphate, chase incubated and analysed by SDS-PAGE, followed by quantitation of mature $\left[{ }^{35} \mathrm{~S}\right]-$ labelled MUC2. For quantitation of total MUC2, which includes non-radiolabelled and radiolabelled MUC2, dot blotting was performed, using a MUC2 monoclonal antibody.
\end{abstract}

Results-Between patient groups, no significant differences were found in $\left[{ }^{35} \mathrm{~S}\right]$-sulphate content of secreted MUC2 or in the secreted percentage of either $\left[{ }^{35}\right.$ S]-amino acid labelled MUC2 or total MUC2. During active ulcerative colitis, secretion of $\left[{ }^{35} \mathbf{S}\right]$-sulphate labelled MUC2 was significantly increased twofold, whereas $\left[{ }^{35} \mathbf{S}\right]$-sulphate incorporation into MUC2 was significantly reduced to half.

Gastroenterology and Nutrition, Department of Pediatrics,

University of

Amsterdam, Academic

Medical Centre,

Amsterdam, The

Netherlands

B J-W Van Klinken

J-W G Van der Wal

Pediatric

Gastroenterology and

Nutrition, Department

of Pediatrics, Sophia

Children's Hospital,

Erasmus University,

Rotterdam, The

Netherlands

A W C Einerhand

H A Büller

J Dekker

Correspondence to: Dr J Dekker, Pediatric Gastroenterology and Nutrition, Laboratory of Pediatrics, Rm Ee-1571b, Dr Molewaterplein 50, 3015 GE Rotterdam, The Netherlands.

Accepted for publication 15 October 1998 orm the structural components of mucus, ${ }^{34}$ changes in the quantity or composition of secreted mucins in the colon could lead to diminished protection of the colonic mucosa, and thus play a role in the pathogenesis of ulcerative colitis. Indeed, in active ulcerative colitis, a number of specific changes have been reported: the mucus gel layer is thinner than normal, and goblet cells, which synthesise the secretory mucins, contain less mucin and also seem to be reduced in number. ${ }^{5-7}$ In remission, the number and appearance of goblet cells returns to normal. ${ }^{8}$ Furthermore, alterations in $\mathrm{O}$-glycosylation of mucins have been reported in ulcerative colitis, such as in sialic acids and in sulphation. ${ }^{9-11}$ Importantly, alterations in glycosylation of mucins, or in sulphation, may lead to a decreased protective capability of the colonic mucus barrier. ${ }^{1213}$

In man, mucins are encoded by a family of at least nine genes, of which the members are designated MUC1-8, including MUC5B and MUC5AC. ${ }^{4}$ We have previously identified MUC2 as the predominant secretory mucin in the normal colon and also in the colon affected by ulcerative colitis. ${ }^{14} 15$ In the efforts to understand the possible roles of colonic mucus in the pathogenesis of ulcerative colitis it is essential to concentrate on the MUC2 gene product. We have recently developed methods to quantify MUC2 biosynthesis in biopsy specimens obtained by endoscopy by performing metabolic labelling with radiolabelled amino acids. ${ }^{16-19} \mathrm{We}$ showed that in active ulcerative colitis, MUC2 synthesis was significantly lowered to less than $40 \%$, compared with both ulcerative colitis in remission and controls, whereas the MUC2 mRNA level remained constant, independently of the disease state. ${ }^{16}$ However, it could not be determined whether secretion of MUC2 is altered in ulcerative colitis.

The aim of this study was to analyse whether sulphation and secretion of MUC2 are altered in ulcerative colitis, as such alterations may lead to diminished protection of the colonic mucosa. Therefore, we quantified the secretion and the sulphate incorporation of MUC2 in patients with active ulcerative colitis, ulcerative colitis in remission, and control patients. This was performed by metabolic labelling of colonic biopsy specimens, using $\left[{ }^{35} \mathrm{~S}\right]$-amino acids and $\left[{ }^{35} \mathrm{~S}\right]$-sulphate and by dot blot analysis, using an anti-MUC2 monoclonal antibody, followed by incubation with $\left[{ }^{125} \mathrm{I}\right]$-protein A. The results show that in active ulcerative colitis, less MUC2 is secreted as MUC2 synthesis is decreased in active ulcerative colitis, while the secreted percentage of MUC2

Abbreviations used in this paper: UC, ulcerative colitis; EMEM, Eagle's minimum essential medium; SDS-PAGE, sodium dodecyl sulphate polyacrylamide gel electrophoresis; PAS, periodic acid/Schiff. 
remains unaltered. This is indicative for a specifically diminished mucosal protection in the ulcerative colitis colon. Additionally, in active ulcerative colitis, MUC2 is also undersulphated, while sulphated MUC2 is selectively secreted. As a result the sulphate content of secreted MUC2 is unaltered in active ulcerative colitis by a specific compensatory mechanism. As the data for both ulcerative colitis in remission and controls differ significantly from the data for active ulcerative colitis, these aberrations are specific for the phase of active inflammation.

\section{Materials and methods}

Unless otherwise stated, chemicals were obtained from the following manufacturers: Gibco BRL, Gaithersburg, Maryland; Sigma, St Louis, Missouri; BioRad, Richmond, California; Amersham, Bucks, UK; and Kodak, Rochester, New York, USA.

HUMAN TISSUES

The following three patient groups were defined according to the accepted criteria of Truelove and Richards, ${ }^{20}$ using clinical, endoscopic, and histological criteria: (1) control patients $(n=12$, seven men; mean age 47 years, range 20-75) who had a negative history for inflammatory bowel disease and had a normal colon. These patients were diagnosed with irritable bowel syndrome, hyperplastic polyps, or diverticulosis. (2) Patients with active ulcerative colitis $(n=13$, six men; mean age 41 years, range 10-68), showing mild to severe inflammation. (3) Patients with ulcerative colitis in remission $(n=7$, four men; mean age 37 years, range 14-75); mean duration of remission was six months. Patients with active ulcerative colitis and ulcerative colitis in remission were receiving medical treatment such as 5-aminosalicylic acid derivatives alone or in combination with steroids. Three patients with active ulcerative colitis did not receive any medical treatment at the moment of endoscopy. Four biopsy specimens were taken from the sigmoid region, at $30 \mathrm{~cm}$ from the anal ring, of each patient. The specimens were metabolically labelled with either $\left[{ }^{35} \mathrm{~S}\right]$-methionine/ cysteine or $\left[{ }^{35} \mathrm{~S}\right]$-sulphate. The use of human tissues was approved by the human research review committee of our institution.

METABOLIC LABELLING

Two biopsy specimens from each patient were metabolically labelled with $\left[{ }^{35} \mathrm{~S}\right]$-methionine/ cysteine to label proteins, including MUC2 precursors, and two specimens were metabolically labelled with $\left[{ }^{35} \mathrm{~S}\right]$-sulphate to label glycoproteins, particularly mature mucin. Metabolic labelling was performed as described previously. ${ }^{14-16} 21$ Briefly, two biopsy specimens were placed together in $100 \mu \mathrm{l}$ tissue culture medium devoid of either methionine/cysteine or sulphate and pulse labelled for 45 minutes by adding, respectively, $100 \mu \mathrm{Ci}\left[{ }^{35} \mathrm{~S}\right]-$ methionine/cysteine (Pro-Mix, Amersham) or $100 \mu \mathrm{Ci}\left[{ }^{35} \mathrm{~S}\right]$-sulphate (Amersham). All biopsy specimens were then washed in medium to remove excess label and each specimen was chase incubated separately for four hours in $100 \mu \mathrm{l}$ medium devoid of radiolabel, but containing non-radiolabelled cysteine/methionine and sulphate. All incubations took place in Eagle's minimum essential medium (EMEM, Gibco BRL) supplemented with EMEM non-essential amino acids (Sigma), penicillin/streptomycin (Sigma), and glutamine (Sigma) at $37^{\circ} \mathrm{C}$ under $95 \% \mathrm{O}_{2} / 5 \% \mathrm{CO}_{2}$. All biopsy specimens or media were homogenised separately at $0^{\circ} \mathrm{C}$ in, respectively, $500 \mu \mathrm{l}$ or $100 \mu$ homogenisation buffer containing Triton X-100 (BDH, Poole, UK) and various protease inhibitors. The homogenates were stored at $-70^{\circ} \mathrm{C}$ until further analysis as described in the following sections.

MEASUREMENT OF PROTEIN SYNTHESIS

Protein content was measured in the homogenate of each biopsy specimen, using a BCA protein assay kit and bovine serum albumin as a standard (Pierce, Rockford, Illinois, USA). Total incorporation of radioactivity in proteins was determined by liquid scintillation counting after trichloroacetic acid precipitation, as previously described. ${ }^{16}$

QUANTITATION OF RADIOLABELLED MUC2

This quantitation protocol has been described by Dekker et al..$^{17-19}$ By performing metabolic labelling of colonic biopsy specimens we have previously shown the biosynthesis and intracellular processing of MUC2. ${ }^{14}{ }^{1521}$ We showed that after pulse labelling with $\left[{ }^{35} \mathrm{~S}\right]$-methionine/ cysteine followed by a four hour chase incubation, almost all radiolabelled MUC2 precursor had become mature O-glycosylated MUC2, which is detectable as a band of about 550 $\mathrm{kDa}$. For the quantitation of $\left[{ }^{35} \mathrm{~S}\right]$-sulphate and $\left[{ }^{35} \mathrm{~S}\right]$-methionine/cysteine labelled mature MUC2, equal aliquots of each radiolabelled homogenate were analysed by reducing sodium dodecyl sulphate polyacrylamide gel electrophoresis (SDS-PAGE) with a 3\% stacking and $4 \%$ running gel. Prestained molecular mass markers in the range 49.5 to $205 \mathrm{kDa}$ (BioRad) were used. For reference to very high molecular mass molecules, metabolically labelled, unreduced rat gastric mucin precursors were used (molecular mass of monomer and dimer, 300 and $600 \mathrm{kDa}$, respectively). ${ }^{22}$ Gels were fixed in $10 \%$ methanol $/ 10 \%$ acetic acid, stained with periodic acid/Schiff's reagent (PAS, Sig$\mathrm{ma}$ ), dried and then used for quantitation of the MUC2 band by autoradiography using a PhosphorImager with ImageQuant software (Molecular Dynamics, B\&L systems, Zoetermeer, The Netherlands). The elicited signal was expressed in arbitrary units. In addition, gels were exposed to $x$ ray film (Biomax MR, Kodak).

The secreted percentage of MUC2 was calculated as the amount of MUC2 in the medium divided by the sum of the amount of MUC2 in the tissue and in the medium. This was multiplied by 100 to give the secreted percentage of MUC2. These values were calculated for $\left[{ }^{35} \mathrm{~S}\right]$-sulphate labelled and $\left[{ }^{35} \mathrm{~S}\right]-$ methionine/cysteine labelled MUC2. To determine $\left[{ }^{35} \mathrm{~S}\right]$-sulphate incorporation into 
MUC2, the sum of the amount of $\left[{ }^{35} \mathrm{~S}\right]-$ sulphate labelled MUC2 in tissue and media homogenates was divided by the sum of the amount of $\left[{ }^{35} \mathrm{~S}\right]$-amino acid labelled MUC2 in tissue and media homogenates. For each patient, the $\left[{ }^{35} \mathrm{~S}\right]$-sulphate incorporation into MUC2 was corrected for differences in protein content between the individual biopsy specimens. To determine the $\left[{ }^{35} \mathrm{~S}\right]$-sulphate content of secreted MUC2, the amount of $\left[{ }^{35} \mathrm{~S}\right]-$ sulphate labelled MUC2 in the medium was divided by the amount of $\left[{ }^{35} \mathrm{~S}\right]$-amino acid labelled MUC2 in the medium. To determine the $\left[{ }^{35} \mathrm{~S}\right]$-sulphate content of MUC2 that was not secreted, the amount of $\left[{ }^{35} \mathrm{~S}\right]$-sulphate labelled MUC2 in the tissue homogenate was divided by the amount of $\left[{ }^{35} \mathrm{~S}\right]$-amino acid labelled MUC2 in the tissue homogenate. For each patient, the $\left[{ }^{35} \mathrm{~S}\right]$-sulphate content of MUC2 was corrected for differences in protein content between the individual biopsy specimens.

QUANTITATION OF TOTAL MUC2

This quantitation protocol has been described by Dekker et al. ${ }^{17}$ In order to analyse the total MUC2 (both radiolabelled and nonradiolabelled MUC2), dot blotting was performed. A $10 \mu \mathrm{l}$ aliquot of ${ }^{35} \mathrm{~S}$-labelled homogenate was dot blotted onto nitrocellulose (Nitran, Schleier \& Schuell, Dassel, Germany). ${ }^{16}$ Briefly, the blot was incubated with a specific anti-MUC2 monoclonal antibody (WE9) which recognises the non-O-glycosylated unique termini of MUC2 ${ }^{17}{ }^{23}$ After washing, the blot was incubated for two hours with ${ }^{125}$ I-labelled protein A (Amersham, specific activity $17.0 \mathrm{mCi} / \mu \mathrm{g})$. Binding of ${ }^{125} \mathrm{I}-$ labelled protein $\mathrm{A}$ to the monoclonal antibody WE9 was detected by autoradiography using a PhosphorImager (expressed in arbitrary units), after the blot was covered by two sheets of $3 \mathrm{MM}$ Whatman filter paper in order to eliminate background radiation of ${ }^{35} \mathrm{~S}$-label. For each biopsy specimen, the secreted percentage of MUC2 was calculated as the amount of MUC2 in the medium divided by the sum of the amount of MUC2 in the tissue and in the medium. This was multiplied by 100 to give the secreted percentage of MUC2.

STATISTICAL ANALYSIS

Analysis of variance was performed, followed by an unpaired $t$ test. Differences were considered significant at $p<0.05$. Data were represented as mean (SEM).

\section{Results}

CHARACTERISTICS OF THE BIOPSY SPECIMENS

To correct for possible differences in size and in labelling efficiencies between the biopsy specimens, the protein content and incorporation of radiolabel of the specimens were determined. A measure of these parameters is the total protein synthesis, referred to as the viability, which is expressed as incorporated ${ }^{35} \mathrm{~S}$-label $(\mathrm{cpm})$ per $\mu \mathrm{g}$ of tissue protein. Average viabilities of the biopsy specimens of each patient were calculated, followed by calculation of the mean viabilities (SEM) for each of the three patient groups. Between controls (mean 5145 (1452) $\mathrm{cpm} / \mu \mathrm{g}$ ), active ulcerative colitis (mean 4391 (833) $\mathrm{cpm} / \mu \mathrm{g}$ ), and ulcerative colitis in remission (mean $3415(769) \mathrm{cpm} / \mu \mathrm{g}$ ) no significant differences in viability were found. Between the duplicate biopsy specimens per patient, the viability differed by only about $15 \%$ in each patient group.

IDENTIFICATION OF MATURE MUC2 IN COLONIC HOMOGENATES

By performing immunoprecipitations after pulse labelling of colonic biopsy specimens with $\left[{ }^{35} \mathrm{~S}\right]$-methionine/cysteine followed by a four hour chase incubation, we previously showed that almost all radiolabelled MUC2 precursor had become mature O-glycosylated MUC2, which is detectable at about $550 \mathrm{kDa}$ on SDS-PAGE. ${ }^{14} 152123$ Furthermore, we showed that this $550 \mathrm{kDa}$ band was PAS stainable and, after western blotting, was recognised by anti-MUC2 antibodies. In fact, the expected molecular mass of mature MUC2 would be more than $2000 \mathrm{kDa}$. However, we showed that this mature mucin has an aberrantly high mobility on SDS-PAGE. ${ }^{14}{ }^{24}$ In the present study, mature MUC2 could also be identified by PAS staining on SDS-PAGE (fig 1). After pulse labelling with $\left[{ }^{35} \mathrm{~S}\right]$-amino acids (fig $2 \mathrm{~A}$ ) or $\left[{ }^{35} \mathrm{~S}\right]$-sulphate (fig $2 \mathrm{~B}$ ), four hour chase incubation and homogenisation, $\left.{ }^{35} \mathrm{~S}\right]$-labelled mature MUC2 was detected on SDS-PAGE at an identical position (about $550 \mathrm{kDa}$ ) as the PAS stained band shown in fig 1 . This is in line with our previous studies, ${ }^{14221}$ showing that both $\left[{ }^{35} \mathrm{~S}\right]$-methionine/cysteine and $\left[{ }^{35} \mathrm{~S}\right]-$ sulphate labelled bands detected after four hour chase incubation, and migrating at 550 $\mathrm{kDa}$ on SDS-PAGE, represent mature MUC2. Mature MUC2 was detected in tissue homogenates and in their corresponding media homogenates in each patient of the three different groups: active ulcerative colitis, ulcerative colitis in remission, and controls (fig $2 \mathrm{~A}, \mathrm{~B}$ ).

QUANTITATION OF SECRETION OF TOTAL MUC2 To quantify the secreted percentage of total MUC2, the homogenates of all ${ }^{35}$ S-labelled biopsy specimens and their corresponding media were dot blotted and thereafter incubated with an anti-MUC2 monoclonal antibody and ${ }^{125} \mathrm{I}$-labelled protein $\mathrm{A}$, followed by quantitation. The secreted percentage of MUC2 was calculated and the values corresponding to the quadruplicate specimens of each patient were averaged and the mean total MUC2 secretion was calculated per patient group (fig 3). For the three patients groups the mean total MUC2 secretion was in the range $28-30 \%$. Between controls, active ulcerative colitis, and ulcerative colitis in remission no significant differences in the secreted percentage of total MUC2 were found (fig 3).

QUANTITATION OF SECRETION OF $\left[{ }^{35} \mathrm{~s}\right.$ ]-AMINO ACID LABELLED MUC2 AND OF $\left[{ }^{35} \mathrm{~s}\right]$-SULPHATE LABELLED MUC2

After analysis on SDS-PAGE, as shown in figs 1 and 2 , the amount of $\left[{ }^{35} \mathrm{~S}\right]$-amino acid labelled MUC2 or $\left[{ }^{35} \mathrm{~S}\right]$-sulphate labelled MUC2 in each biopsy specimen, and in its 
corresponding medium were quantified. Firstly, the secreted percentage of $\left[{ }^{35} \mathrm{~S}\right]$-amino acid labelled or $\left[{ }^{35} \mathrm{~S}\right]$-sulphate labelled MUC2

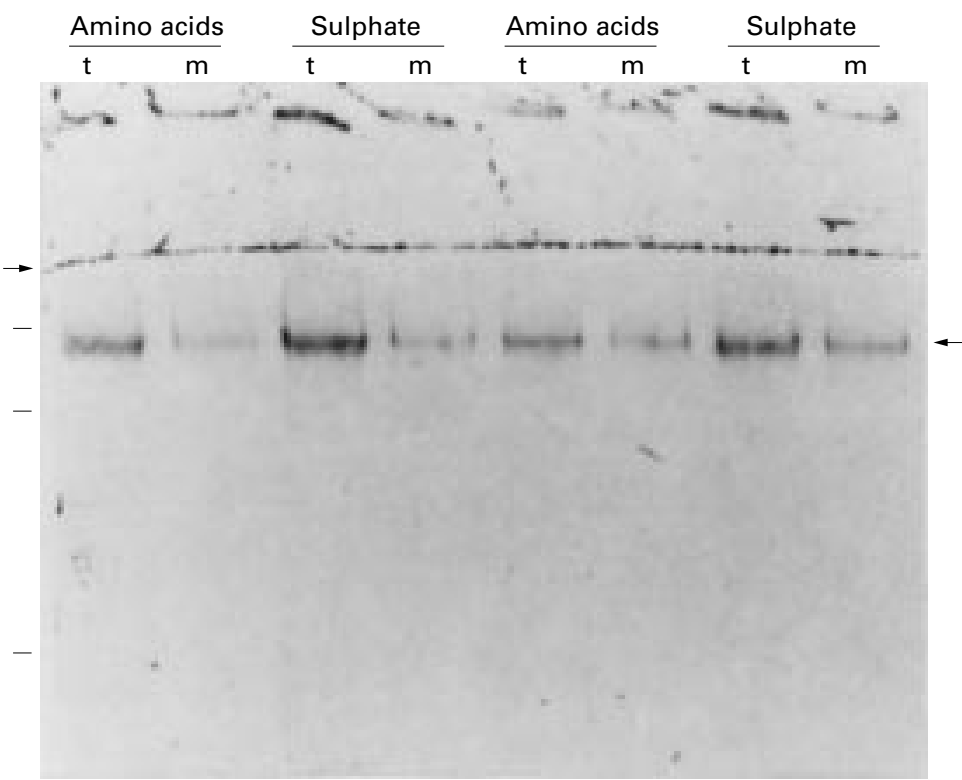

Figure 1 PAS staining of mature MUC2. A representative example of analyses of duplicate biopsy specimens of one control patient. After pulse labelling with either

$\left.{ }^{35} S\right]$-amino acids or $\left[^{35} S\right]$-sulphate and four hour chase incubations, the homogenates of the tissue $(t)$ and the media $(m)$ were analysed on reducing $4 \%$ SDS-PAGE and stained with PAS. The right hand arrow indicates the position of mature MUC2. The left hand arrow denotes the border between the running and stacking gel. Molecular mass markers of 600, 300 , and $205 \mathrm{kDa}$ are indicated on the left. was calculated per specimen. Then, for every patient, the average secretion of $\left[{ }^{35} \mathrm{~S}\right]$-amino acid labelled MUC2 per patient was calculated from the duplicate specimens (fig 4 ). In a similar way the average secretion of the $\left[{ }^{35} \mathrm{~S}\right]-$ sulphate labelled MUC2 was also calculated (fig 5). In controls, active ulcerative colitis, and ulcerative colitis in remission no significant differences were found in the mean secreted percentage of $\left[{ }^{35} \mathrm{~S}\right]$-amino acid labelled MUC2 (fig 4). The mean secreted percentage of $\left[{ }^{35} \mathrm{~S}\right]-\mathrm{a}-$ mino acid labelled MUC2 was in the range of $22-24 \%$ in all three patient groups. However, between patient groups significant differences in secretion of $\left[{ }^{35} \mathrm{~S}\right]$-sulphate labelled MUC2 were found (fig 5). In active ulcerative colitis the secreted percentage of $\left[{ }^{35} \mathrm{~S}\right]$-sulphate labelled MUC2 was significantly increased more than twofold compared with ulcerative colitis in remission $(\mathrm{p}<0.001)$ and controls $(\mathrm{p}<0.02)$. The difference between controls and ulcerative colitis in remission was small and statistically not significant (fig 5). The increase in secretion of $\left[{ }^{35} \mathrm{~S}\right]$-sulphate labelled MUC2 is also visible on SDS-PAGE (fig 2B). During active ulcerative colitis, the amount of $\left[{ }^{35} \mathrm{~S}\right]$-sulphate labelled MUC2 in the medium is larger than the amount of $\left[{ }^{35} \mathrm{~S}\right]$-sulphate labelled MUC2 in the tissue homogenate, whereas in controls or ulcerative colitis in remission the amount of $\left[{ }^{35} \mathrm{~S}\right]$-sulphate labelled MUC2 in the medium is
A

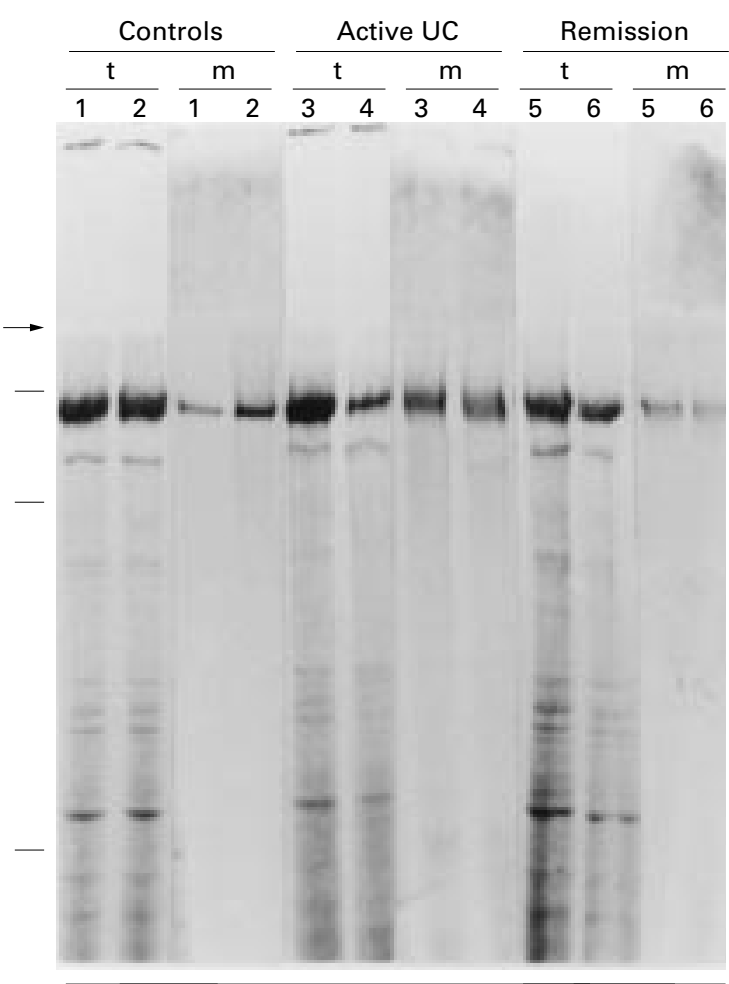

${ }^{35} \mathrm{~S}$-amino acids
B

$\frac{\mathrm{t}}{\frac{\mathrm{t}}{12} \frac{\mathrm{m}}{14}} \frac{\mathrm{t}}{34} \frac{\mathrm{m}}{34} \frac{\mathrm{t}}{5 \quad 6} \frac{\mathrm{m}}{5 \quad 6}$
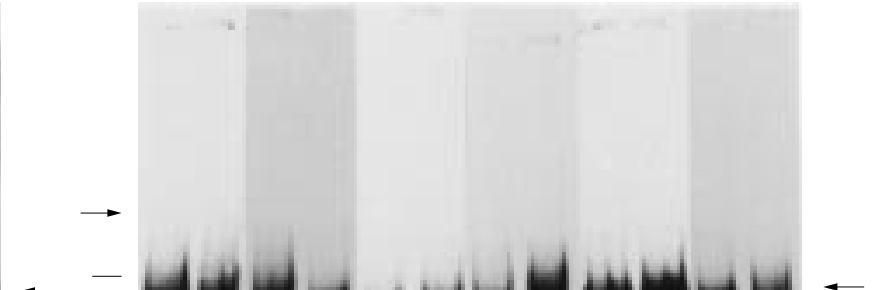

${ }^{35} \mathrm{~S}$-sulphate

Figure 2 Identification of mature MUC2 in colonic homogenates. Representative examples of analyses of the biopsy specimens of each patient group are shown: controls (specimens 1 and 2), active ulcerative colitis (UC) (specimens 3 and 4), or ulcerative colitis in remission (specimens 5 and 6). Specimens were pulse labelled with either (A) $P^{5} S J$-amino acids (two duplicate specimens per patient) or (B) ${ }^{5} S$ ST-sulphate (two duplicate specimens per patient) and chase incubated for four hours, followed by analysis of the homogenates of the tissue (lanes $t$ ) and of the media (lanes $m$ ) on 4\% reducing SDS-PAGE. The radioactive signal of the mature MUC2 band, indicated by the right hand arrows, was quantified using a PhosphorImager, followed by exposure to $x$ ray film (shown here). The left hand arrows denote the border between the running and stacking gel. Molecular mass markers of 600, 300, and 205 kDa are indicated on the left. 


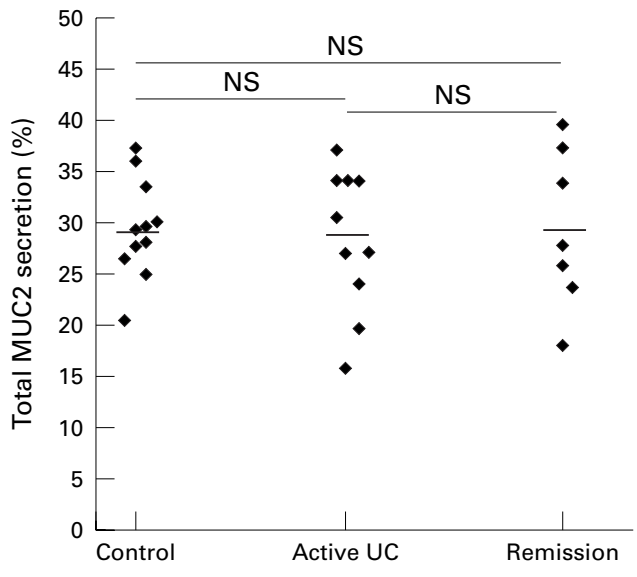

Figure 3 Secretion of total MUC2. All ${ }^{35}$ S-labelled homogenates were dot blotted and incubated with an anti-MUC2 monoclonal antibody and ${ }^{125}$ I-labelled protein $A$. The elicited ${ }^{125}$ I signal was then quantified and the secreted percentage of total MUC2 was calculated. Average values were then calculated per patient from the

quadruplicate values of the biopsy specimens, and the mean values per patient group were subsequently calculated. Each point represents the average value of one patient. Mean (SEM) value per patient group: controls (29.5 (1.41)\%), active ulcerative colitis (UC) (28.5 (2.21)\%) and ulcerative colitis in remission (29.4 (2.9)1\%). Horizontal bars denote the mean of each patient group.

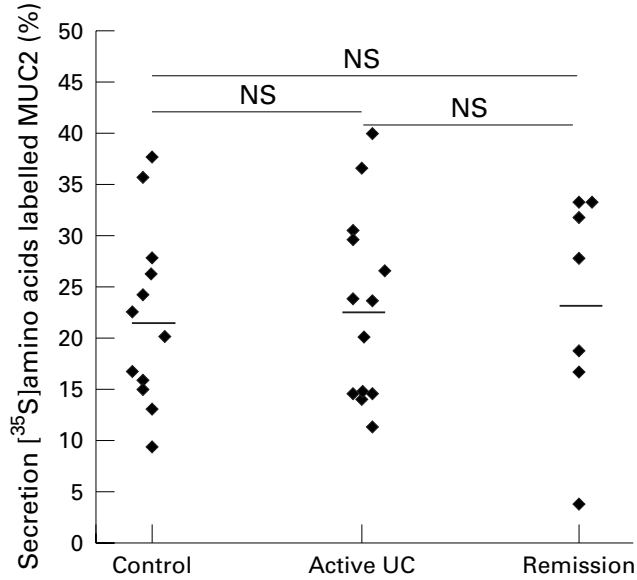

Figure 4 Secretion of $\left[^{35}\right.$ S]-amino acid labelled MUC2. $\left.{ }^{35} S\right]$-amino acid labelled homogenates were analysed on reducing SDS-PAGE, and the MUC2 band was quantified. The secreted percentage of MUC2 was calculated per biopsy specimen. Average values were calculated per patient from the duplicate values of the specimens, and the mean values per patient group were determined. Each point represents the average value of one patient. Mean (SEM) values per patient group: controls (22.17 (2.55)\%), active ulcerative colitis (UC) (23.08 $(2.55) \%)$ and ulcerative colitis in remission (23.47

(4.16)\%). Horizontal bars denote the mean of each patient group.

less than or equal to the quantity of $\left[{ }^{35} \mathrm{~S}\right]-$ sulphate labelled MUC2 in the tissue homogenates.

QUANTITATION OF $\left[{ }^{35}\right.$ S $]$-SULPHATE

INCORPORATION INTO MUC2

To determine the $\left[{ }^{35} \mathrm{~S}\right]$-sulphate incorporation into MUC2, the sum of the quantities of $\left[{ }^{35} \mathrm{~S}\right]-$ sulphate labelled MUC2 in the tissue and media homogenates was expressed relative to the sum of the quantities of $\left[{ }^{35} \mathrm{~S}\right]$-amino acids labelled MUC2 in tissue and media homogenates (fig 6). In active ulcerative colitis, $\left[{ }^{35} \mathrm{~S}\right]-$ sulphate incorporation into MUC2 was signifi-

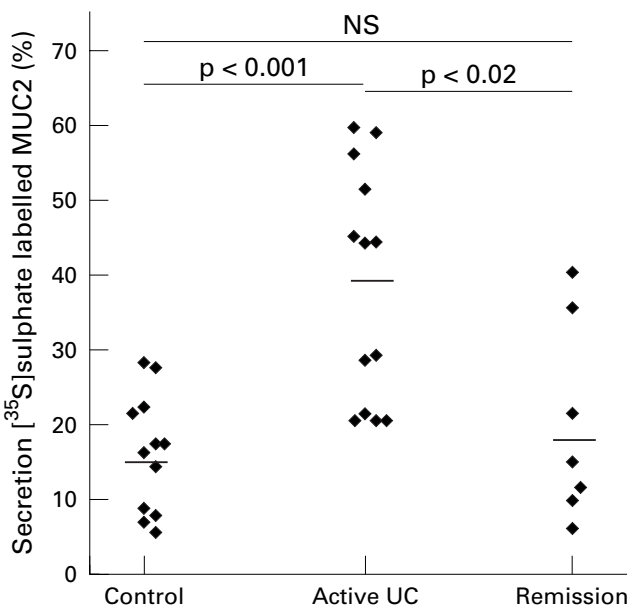

Figure 5 Secretion of $\left.{ }^{35} S\right]$-sulphate labelled MUC2. $\left.{ }^{35} S\right]-$ sulphate labelled homogenates were analysed on reducing SDS-PAGE, and the MUC2 band was quantified. The secreted percentage of MUC2 was calculated per biopsy specimen. Average values were calculated per patient from the duplicate values of the specimens, and the mean values per patient group were determined. Each point represents the average value of one patient. Mean (SEM) values per patient group: controls (16.23 (2.27)\%), active ulcerative colitis (UC) (38.63 (4.3) \%) and ulcerative colitis in remission (19.97 (2.27)\%). Horizontal bars denote the mean of each patient group.

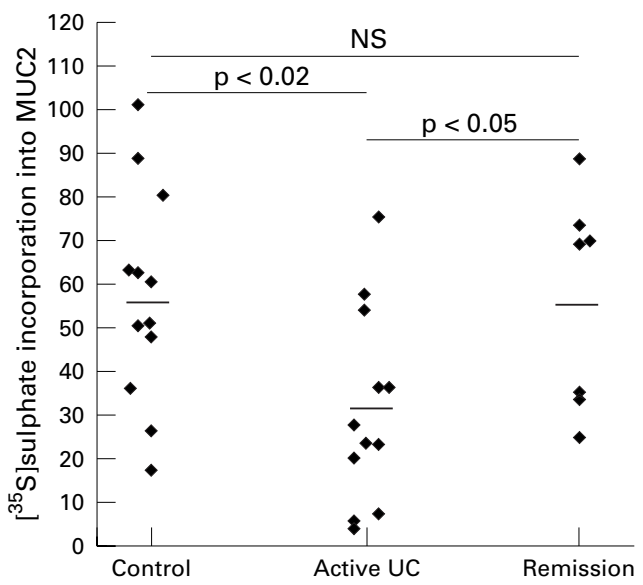

Figure $6\left[{ }^{35} S\right]$-sulphate incorporation into MUC2. To determine $\left.{ }^{35} S\right]$-sulphate incorporation into MUC2, the sum of the amounts of [ $\left.{ }^{35} S\right]$-sulphate labelled MUC2 in tissue and media homogenates was expressed relative to the sum of the amounts of [35]-amino acid labelled MUC2 in tissue and media homogenates. Each point represents one patient. Mean (SEM) values per patient group: controls (57.35 (7.1)), active ulcerative colitis (UC) (31.04 (6.43)) and ulcerative colitis in remission (56.63 (9.28)). Horizontal bars denote the mean of each patient group.

cantly reduced to half, compared with ulcerative colitis in remission $(\mathrm{p}<0.05)$ and controls $(p<0.02)$ (fig 6$)$. No significant difference in $\left[{ }^{35} \mathrm{~S}\right]$-sulphate incorporation into MUC2 was found between ulcerative colitis in remission and controls.

QUANTITATION OF $\left[{ }^{35} \mathrm{~s}\right]$-SULPHATE CONTENT OF SECRETED MUC2

To determine the $\left[{ }^{35} \mathrm{~S}\right]$-sulphate content of secreted MUC2, the amount of $\left[{ }^{35} \mathrm{~S}\right]$-sulphate labelled MUC2 in the medium was expressed relative to the amount of $\left[{ }^{35} \mathrm{~S}\right]$-amino acid labelled MUC2 in the medium (fig 7). Interestingly, between active ulcerative colitis, ulcerative 


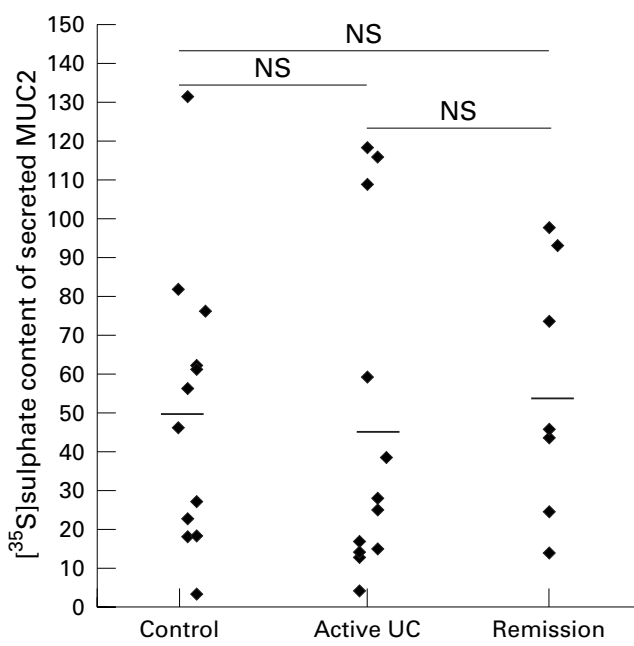

Figure $7 \quad{ }^{35}$ SJ-sulphate content of secreted MUC2. To determine $\left.{ }^{35} S\right]$-sulphate content of secreted MUC2, the amount of ["SJ-sulphate labelled MUC2 in the medium was expressed relative to the amount of $\left[^{35} S\right]$-amino acid labelled MUC2 in the medium. Each point represents one patient. Mean (SEM) values per patient group: controls (50.23 (10.33)), active ulcerative colitis (UC) (46.14 (12.59)) and ulcerative colitis in remission (55.91 (12.5)). Horizontal bars denote the mean of each patient group.

colitis in remission, and controls no significant was difference found in the $\left[{ }^{35} \mathrm{~S}\right]$-sulphate content of secreted MUC2. To determine the $\left[{ }^{35} \mathrm{~S}\right]$-sulphate content of MUC2 that was not secreted, the amount of $\left[{ }^{35} \mathrm{~S}\right]$-sulphate labelled MUC2 in the tissue homogenates was expressed relative to the amount of $\left[{ }^{35} \mathrm{~S}\right]$-amino acid labelled MUC2 in the tissue homogenates. In active ulcerative colitis, $\left[{ }^{35} \mathrm{~S}\right]$-sulphate content of MUC2 in the tissue homogenates was significantly reduced compared with controls and with ulcerative colitis in remission (not shown).

In the different patient groups, no correlation was found between any of the determined parameters (viability, secretion, $\left[{ }^{35} \mathrm{~S}\right]-$ amino acid incorporation, $\left[{ }^{35} \mathrm{~S}\right]$-sulphate incorporation into $\mathrm{MUC} 2$, and $\left[{ }^{35} \mathrm{~S}\right]$-sulphate content of MUC2) and sex or age of the individual patients in the various groups (not shown).

\section{Discussion}

As MUC2 is the prominent mucin in healthy colon and in colon affected by ulcerative colitis, ${ }^{14}{ }^{15}$ and because mucins play an important role in cytoprotection, ${ }^{25}$ we aimed to investigate possible alterations in biosynthesis or secretion of MUC2 in ulcerative colitis. Previously, we showed that the synthesis of MUC2 was decreased in active ulcerative colitis, compared with ulcerative colitis in remission and controls. ${ }^{16}$ Following a similar quantitation protocol, we now set out to investigate whether the secretion or sulphation of MUC2 is altered in ulcerative colitis. Three comparable patient groups were studied: active ulcerative colitis, ulcerative colitis in remission, and a control group. In all patients, biopsy specimens were obtained from the same anatomically defined region of the colon. Firstly, we determined the viabilities of the specimens, and showed that these did not differ significantly between the patient groups. This is similar to our previous results, ${ }^{16}$ which showed that total protein synthesis of biopsy specimens did not change during short term in vitro culture, or between patients with active ulcerative colitis, ulcerative colitis in remission, or controls.

Metabolic labelling with $\left[{ }^{35} \mathrm{~S}\right]$-amino acids was performed to determine secretion of mature $\left[{ }^{35} \mathrm{~S}\right]$-amino acid labelled MUC2. By this kind of analysis we were able to determine the secreted percentage of biosynthesised MUC2. In active ulcerative colitis, the secreted percentage of the $\left[{ }^{35} \mathrm{~S}\right]$-amino acid labelled MUC2 remained unaltered compared with ulcerative colitis in remission and controls. To investigate the secretion of MUC2 further, dot blotting was performed. By these analyses we were able to quantify the secretion of both radiolabelled and non-radiolabelled MUC2. Between the three patient groups no significant differences were found in secreted percentage of total MUC2. Thus, by two independent methods we were able to show that the secreted percentage of MUC2 remained unaltered during active ulcerative colitis. Previously, we showed that MUC2 synthesis, as measured by the incorporation of $\left[{ }^{35} \mathrm{~S}\right]$-amino acids, is lowered approximately threefold in active ulcerative colitis compared with ulcerative colitis in remission and controls. ${ }^{16}$ We have now shown that the secreted percentage of MUC2 is unaltered during active ulcerative colitis, and it therefore follows that the quantity of luminal MUC2 (the secreted MUC2) will be about threefold less during active ulcerative colitis. Therefore, the colonic mucus gel layer will contain less MUC2, and is thus thinner, weaker, and less protective in active ulcerative colitis. Interestingly, our findings explain the results of Pullan et al, who showed that the thickness of the colonic mucus gel is decreased in active ulcerative colitis. ${ }^{5}$

Metabolic labelling with $\left[{ }^{35} \mathrm{~S}\right]$-sulphate was performed to study secretion of $\left[{ }^{35} \mathrm{~S}\right]$-sulphate labelled MUC2, $\left.{ }^{35} \mathrm{~S}\right]$-sulphate incorporation into MUC2, and the $\left[{ }^{35} \mathrm{~S}\right]$-sulphate content of MUC2 in tissue and media. Sulphate is incorporated in the last steps of mucin biosynthesis before either storage or secretion takes place. ${ }^{25}$ In active ulcerative colitis, the secreted percentage of $\left[{ }^{35} \mathrm{~S}\right]$-sulphate labelled MUC2 was increased about twofold compared with ulcerative colitis in remission and controls. Thus, $\left[{ }^{35} \mathrm{~S}\right]$-sulphate labelled MUC2 is preferentially secreted in active ulcerative colitis. However, our results also showed that $\left[{ }^{35} \mathrm{~S}\right]$-sulphate incorporation into MUC2 is reduced to half during active ulcerative colitis. This is in line with previous studies that suggested that less sulphate was incorporated into colonic mucus during active ulcerative colitis. ${ }^{10}{ }^{11}$ However, in those studies secretion of sulphated MUC2 was not specifically quantified. Our results show that the decreased incorporation of $\left[{ }^{35} \mathrm{~S}\right]-$ sulphate into MUC2 is compensated for by the increased secretion of $\left[{ }^{35} \mathrm{~S}\right]$-sulphate labelled MUC2. As a result, no significant differences were found in $\left[{ }^{35} \mathrm{~S}\right]$-sulphate content of secreted MUC2 between active ulcerative colitis, 
ulcerative colitis in remission, and controls. We showed that, although less sulphate is incorporated into MUC2 during active ulcerative colitis, the net effect on the sulphate content (a measure of the mean number of sulphate residues per molecule) of the secreted MUC2 is nil, due to specifically enhanced secretion of sulphated MUC2. These results indicate that, in the colon of patients with active ulcerative colitis, the sulphate content of the luminal MUC2 is likely to be similar to that in healthy control patients. Because the alterations in secretion and in sulphation of MUC2 return to normal in ulcerative colitis in remission, they are not the underlying defect in ulcerative colitis. It is important to mention that the kinetics of the secretion of $\left[{ }^{35} \mathrm{~S}\right]$-sulphate labelled MUC2 were not investigated in the present study. For instance, it is unclear whether secretion of $\left[{ }^{35} \mathrm{~S}\right]$-sulphate labelled MUC2 is a more rapid process during active ulcerative colitis, compared with ulcerative colitis in remission or controls. This needs to be studied in the future.

Importantly, sulphate is thought to confer resistance to enzymatic degradation of the mucus barrier ${ }^{13}$ and therefore a decreased sulphate content of the mucus gel layer would be disadvantageous. On the other hand, an increased sulphate content of the mucus would also be disadvantageous, because more sulphate residues would be available to sulphate reducing bacteria. These bacteria are overrepresented in the bacterial flora of the colon during ulcerative colitis and produce sulphides that are highly toxic to the colonic mucosa. ${ }^{26-28}$

The mechanisms that are responsible for the alterations in secretion of $\left[{ }^{35} \mathrm{~S}\right]$-sulphate labelled MUC2 and in $\left[{ }^{35} \mathrm{~S}\right]$-sulphate incorporation into MUC2 are as yet unsolved. Possibly, they are caused by direct effects of inflammatory mediators produced during active ulcerative colitis, on the glycosylation and secretion machinery of the cells. Previous studies showed a decrease in length of the O-linked glycans of mucins in ulcerative colitis ${ }^{12}$ which at least in part could explain the decrease in $\left[{ }^{35} \mathrm{~S}\right]-$ sulphate incorporation into MUC2. Using human colonic cell lines, we are currently investigating the in vitro effect of proinflammatory mediators, such as cytokines, on the secretion of $\left[{ }^{35} \mathrm{~S}\right]$-sulphate labelled MUC2 and on $\left[{ }^{35} \mathrm{~S}\right]$-sulphate incorporation into MUC2.

In conclusion, the colonic mucus barrier will be thinner and therefore less protective during active ulcerative colitis, because the absolute amount of MUC2 that is secreted is diminished. In addition, sulphated MUC2 is preferentially secreted during active ulcerative colitis. However, due to a decreased incorporation of sulphate into MUC2, the sulphate content of the secreted MUC2 (the number of sulphate residues per MUC2 molecule) will probably be normal in patients with active ulcerative colitis. This work was supported by a grant from Astra Pharmaceuticals
BV and the foundation "De Drie Lichten".

1 Podolsky DK. Inflammatory bowel disease. $N$ Engl f Med 1991;13:28-38.

2 Podolsky DK. Inflammatory bowel disease. $N$ Engl f Med 1991;14:1008-17.

3 Forstner JF, Forstner GG. Gastrointestinal mucus. In: Johnson LR, ed. Physiology of the gastrointestinal tract. Vol 2. 3rd son LR, ed. Physiology of the gastrointestinal tract.

4 Van Klinken BJW, Dekker J, Büller HA, et al. Mucin gene structure and expression: protection vs. adhesion. Am $\mathcal{F}$ Physiol 1995;269:G613-27.

5 Pullan RD, Thomas GAO, Rhodes M, et al. Thickness of adherent mucus gel on colonic mucosa in humans and its relevance to colitis. Gut 1994;35:353-9.

6 Jacobs LR, Huber PW. Regional distribution and alterations of lectin binding to colorectal mucin in mucosal biopsies from controls and subjects with inflammatory bowel disease. F Clin Invest 1985;75:112-18.

7 McCormick DA, Horton LW, Mee AS. Mucin depletion in inflammatory bowel disease. F Clin Pathol 1990;43:143-6.

8 Theodossi A, Spiegelhalter D, Jass J, et al. Observer variation and discriminatory value of biopsy features in inflammaand discriminatory value of biopsy fea

9 Parker N, Tsai HH, Ryder SD, et al. Increased rate of sialylation of colonic mucin by cultured ulcerative colitis mucosal explants. Digestion 1995;56:52-6.

10 Raouf AH, Tsai HH, Parker N, et al. Sulfation of colonic mucin in ulcerative colitis and Crohn's disease. Clin Sci 1992;83:623-6.

11 Morita H, Kettlewell MGW, Jewell DP, et al. Glycosylation and sulphation of colonic mucus glycoproteins in patients with ulcerative colitis and healthy subjects. Gut 1993;34: 926-32.

12 Tytgat KMAJ, Dekker J, Büller HA. Mucins in inflammatory bowel disease, Eur f Gastroenterol Hepatol 1993;5:11928.

13 Nieuw Amerongen AV, Bolscher JGM, Bloemena E, et al. Sulfomucins in the human body. Biol Chem 1998;379:1-18.

4 Tytgat KMAJ, Büller HA, Opdam FJM, et al. Biosynthesis of human colonic mucin: MUC2 is the prominent of human colonic mucin: MUC2 is the prom

15 Tytgat KMAJ, Opdam FJM, Einerhand AWC, et al. MUC2 is the prominent colonic mucin expressed in ulcerative colitis. Gut 1996;38:554-63.

16 Tytgat KMAJ, Van der Wal JWG, Einerhand AWC, et al. Quantitative analysis of MUC2 synthesis in ulcerative colitis. Biochem Biophys Res Commun 1996;224:397-405.

17 Dekker J, Van Klinken BJW, Büller HA, et al. Quantitation of mucin biosynthesis and mucin secretion using metabolic labeling. In: Corfield AP, ed. Mucin methods and protocols. Methods in molecular biology series. Totowa, New Jersey:

18 Van Klinken BJW, Büller HA, Einerhand AWC, et al. Identification of mucins using metabolic labeling, immunoprecipitation, and gel electrophoresis. In: Corfield AP, ed. Mucin methods and protocols. Methods in molecular biology series. Totowa, New Jersey: Humana Press (in press)

19 Einerhand AWC, Van Klinken BJW, Büller HA, et al. Mucin precursors: identification and analysis of their intracellular processing. In: Corfield AP ed. Mucin methods and protocols. Methods in molecular biology series. Totowa, New Jersey: Humana Press (in press)

20 Truelove SC, Richards WCD. Biopsy studies in ulcerative colitis. BMF 1956;1:1315-18

21 Van Klinken BJW, De Bolos C, Büller HA, et al. Biosynthesis of mucins (MUC2-6) along the longitudinal axis of the human gastro-intestinal tract. Am f Physiol 1997;273. G296-302.

22 Dekker J, Strous GJ. Covalent oligomerization of rat gastric mucins occurs in the rough endoplasmic reticulum, is $\mathrm{N}$-glycosylation dependent, and precedes O-glycosylation. f Biol Chem 1990;265:18116-22.

23 Tytgat KMAJ, Klomp LWJ, Bovelander FJ, et al. Preparation of anti-mucin polypeptide antisera to study mucin biosyn-
thesis. Anal Biochem 1995;226:331-41.

24 Tytgat KMAJ, Swallow DM, Van Klinken BJW, et al. Unpredictable behaviour of mucins in SDS/polyacrylamide-gel electrophoresis. Biochem f 1995;103:1053-4.

25 Strous GJ, Dekker J. Mucin-type glycoproteins. Crit Rev Biochem Mol Biol 1992;27:57-92.

26 Pitcher, MCL, Beatty ER, Gibson GR, et al. Incidence and activities of sulphate-reducing bacteria in patients with ulcerative colitis [abstract]. Gut 1995;36:A63.

27 Gibson, GR, Cummings JH, Macfarlane GT. Growth and activities of sulphate-reducing bacteria in gut contents of healthy subjects and patients with ulcerative colitis. FEMS Microbiol Ecol 1991;86:103-12.

28 Roediger WEW, Moore J, Babidge W. Colonic sulfide in pathogenesis and treatment of ulcerative colitis. Dig Dis Sci 1997;42:1571-9. 